\title{
An Overview of Applying Surfactants to Modified- Functionalized Nanoporous Materials for Metal Ions Sequestration
}

\author{
Suwimol Wongsakulphasatch \\ Department of Chemical Engineering, Faculty of Engineering and Industrial Technology, \\ Silpakorn University, Nakhon Pathom 73000, Thailand \\ E-mail: suwimol.w@su.ac.th
}

\begin{abstract}
This paper presents an application of surfactants extended to environmental remediation. The promising process related to the use of surfactants for heavy metal sequestration purpose named "modified-functionalized nanoporous materials" is summarized in this work. The unique characteristic of high selective of the functional groups and large surface area of nanoporous support makes this material becomes a powerful tool for sequestration of target metals. The strength of this adsorbent is fast sorption kinetic, high thermal and chemical stability, easy handling, and the ability to regenerate.
\end{abstract}

Keywords: Modified-functionalized nanoporous materials, heavy metal, adsorption.

ENGINEERING JOURNAL Volume 17 Issue 2

Received 10 September 2012

Accepted 23 December 2012

Published 1 April 2013

Online at http://www.engj.org/

DOI:10.4186/ej.2013.17.2.29 


\section{Introduction}

Surface active agents or surfactants are amphipathic molecules consisting of a group that has very little attraction with the solvent, called a lyophobic (liquid-hating) group, and a group that has strong interaction with the solvent, named a lyophilic (liquid-loving) group. At low concentration, surfactants can lower surface tension of the system by adsorbing onto the interfaces and altering the interfacial free energies of those interfaces. At high enough surfactant concentration, surfactant molecules can spontaneously selfaggregate into a variety of structures, which are called micelles. The concentration at which surfactants begin to form micelle is named critical micelle concentration (CMC) $[1,2]$. Because of the unique characteristics of surfactants, surfactants have therefore been applied and played an important role in various products of chemical industry such as detergents, cosmetics, petroleum, electronic printing, pharmaceuticals, medical, food, and environmental applications [2,3]. Surfactants are used as emulsifier in food and cosmetic industries as well as in most of cleaning products such as detergents or soaps [3]. In addition, surfactants can be used to enhance oil recovery by, for example, improving oil drainage into well bore, wetting of solid surfaces, lessening oil viscosity and oil pour point, or lowering the interfacial tension. In the recent past decades, surfactants have been extended the use to environmental area for mainly toxic metal treatment purposes [4-7].

With the recognizing of high performance and versatile of surfactants applied in many industries as well as the concern of environment in the recent decades, the author would therefore like to present the extension of the use of surfactants to environmental applications. Technique related to an application of surfactants to remove metals, named modified-functionalized nanoporous support was summarized in this paper. The paper is organized as follows. First of all, a brief review of the danger of toxic heavy metals and various treatment techniques is presented. Then, environmental treatment technique related to the use of surfactants, named modified-functionalized nanoporous support is introduced. Concluding remark is presented in the last section.

\section{Toxic of Heavy Metals and Treatment Techniques}

Heavy metals are nowadays applied in many industrial technologies and with the fast development of such technologies a large amount of heavy metals are discharged into environment. Excess exposure of heavy metal contaminations can damage environment, animals, and human health as they can enter the food chain when they are either discharged directly or indirectly into the environment. For example, copper, which is mostly found in printed circuit board manufacturing, electronics plating, paint manufacturing, wire drawing, etc., can cause toxicological concerns, such as dizziness, diarrhea, convulsions, neurotoxicity, etc. Exposure of cadmium can result in kidney dysfunction, carcinogenic, itai-itai disease, lung efficiency, or cancer. Sources of cadmium are electroplating, alloy manufacturing, mining, or refining. Mercury is found in the release of fossil fuel burning, battery production, mining and metallurgical process, or paint industries. An uptake of mercury can lead to neurological disturbances, impairment of pulmonary function, or kidney damage. Lead used in battery manufacturing, electroplating, pigments, ammunition, can damage brain, kidney, liver, and central nervous system. Nickel found in mineral processing, electroplating, steam-electric power plants, can result in lung and kidney cancer, gastrointestinal distress, and skin dermatitis $[8,9]$.

Treatment of heavy metals has long been attracted great interest in many areas because of their poison to environment and human health as mention earlier. Various techniques have been developed for metal treatment and their applications depend upon the system of interest. Chemical precipitation is an early technique that is used to remove heavy metal but this technique has disadvantages of which it is expensive, has low selectivity, and is not capable of removing metals at low concentration [10]. Ion exchange or electrochemical methods were developed to enhance the ability to sequestrate metal ions. High metal selectivity can be obtained but high capital and running cost are the major disadvantages of these techniques. Membrane processes, such as nanofiltration (NF) or reverse osmosis (RO), have later been developed to enhance ability of heavy metal ion removal [10]. Although they have high efficiency to separate heavy metal ions but they require high energy consumption and have low permeate flux. The limitation of pump and membrane technology is then drawn a focus on the feasibility of using surfactant to enhance metal ion separation efficiency, maximize metal ion removal capability, and minimize energy used. This technique is called micellar-enhanced ultrafiltration (MEUF) [11]. The use of surfactants can enhance removal efficiency of membrane as the formation of micelle can capture metal ions and form molecule 
complexes, resulting in a reduction of high pressure needed for membrane permeation. Many types of surfactant are used to improve the ability of heavy metal ion removal in any treatment processes, such as, polyoxyethylene nonyl phenyl ethers [12], sodium dodecyl sulfate (SDS) [13], surfactin [14], rhamnolipid [14], etc. High removal efficiency greater than $90 \%$ can be obtained for this technique, however, large amount of surfactants used and less capability of continuous operating due to membrane blockage are the drawback of this technique $[14,15,16]$. Adsorption is another widely used process for toxic metal treatment due to its high efficiency, easy to handle, simple operation, and economical feasibility [3]. Adsorbents, such as carbon nanotubes [17], zeolites [18], activated carbon [19], etc., are commonly used in adsorption process due to high loading capacity and low cost. However, the inherent limitations of these adsorbents are their wide distribution of pore size and heterogeneous pore structure [20]. To improve capability of sorbent materials, a new class of adsorbents, named "modified-functionalized nanoporous support", has been invented and developed [4-7]. Modification of nanoporous surface by organic materials or by surface active agents makes this material become a promising adsorbent for -application to metal sequestration. High selectivity for target metal of chosen its functional groups coupled with high adsorption capacity of porous support can enhance the reduction of metal concentration. As this hybrid adsorbent has emerged recently as a powerful tool for metal ion removal this work is therefore focused on the use of surfactants in this type of adsorbent.

\section{Modified-Functionalized Nanoporous Support}

\subsection{Application to Heavy Metal Ion Adsorption}

One of various techniques that has been developed to enhance the ability of heavy metal removal processes with the application of surfactants is the use of surfactants connected to nanoporous materials, which is known as modified-functionalized nanoporous support [4, 20,21, 22]. The distinctive of this adsorbent relies on the fact that surface of nanoporous material is modified by functional groups containing head groups that can interact selectively with target metal while the nanoporous material provides high surface area, which leads to high binding capacity. This adsorbent provides fast sorption kinetics, high stability, and easy regeneration $[5,21,23]$. Moreover, advantages of such hybrid sorbent materials over other adsorbents like activated carbon or zeolite are their high thermal and chemical stability [24]. Because of the strengthen characteristic of this highly selective sorbent material, it is now recognized as an effective technique for metal removal in the recent decade.

Fryxell et al. [23] studied sequestration of $\mathrm{Pu}(\mathrm{IV})$ using acetamidephosphonate (Ac-Phos) loaded as self-assembled monolayer on mesoporous silica support (SAMMS), named Ac-Phos SAMMS. They considered the performance of the adsorbent in terms of distribution coefficient, a mass-weighted partition coefficient between the solution phase and adsorbent phase, and sorption kinetic. The results showed that the Ac-Phos acid can bind to $\mathrm{Pu}(\mathrm{IV})$ stronger and more rapid than other metal ions i.e. $\mathrm{Ni}(\mathrm{II}), \mathrm{Mn}(\mathrm{II})$, $\mathrm{Fe}(\mathrm{III}), \mathrm{Al}(\mathrm{III}), \mathrm{Zr}(\mathrm{IV})$, and $\mathrm{Mo}(\mathrm{VI})$, in mixed metal solution, as was revealed by high distribution coefficient and fast sorption kinetic. Yantasee et al. [22] studied the adsorption capacity, selectivity, and kinetic of self-assembled monolayers of carbamoylphosphonic acids, acetamide phosphonic acid, and propionamide phosphonic acid, on mesoporous silica support to capture heavy and transition metal ions in aqueous wastes. The results showed that adsorption of metal ions on SAMMS can reach equilibrium within a minute and the binding affinity in decreasing order was found to be $\mathrm{Pb}(\mathrm{II})>\mathrm{Cu}$ (II) $>\mathrm{Mn}$ (II) $>\mathrm{Cd}$ (II) $>$ $\mathrm{Zn}$ (II) $>\mathrm{Co}(\mathrm{II})>\mathrm{Ni}$ (II). Fryxell et al. [25] studied the performance of SAMMS for actinide sequestrating using Glycinyl-urea SAMMS, Ac-Phos ester SAMMS, and phosphonate ester SAMMS (Phop-Phos ester). Glycinyl-urea SAMMS was found that can bind to all of the actinides (Am(III), Pu(IV), Np(V), U(VI), $\mathrm{Th}(\mathrm{IV})$ ) where better binding efficiency occurring at higher $\mathrm{pH}$ values. The Ac-Phos ester SAMMS also can bind effectively for all the actinides of the studies and the distribution coefficients were found to be excess of 20,000, which represents an outstanding adsorbent. However, the Phop-Phos SAMMS was observed that selectively bind to $\mathrm{Pu}(\mathrm{IV})$ at low $\mathrm{pH}$. Lin et al. [26] examined the ability of hydroxypyridinone incorporated with mesoporous silica (HOPO-SAMMS) to sequestrate $\mathrm{U}(\mathrm{VI}), \mathrm{Np}(\mathrm{V})$ and $\mathrm{Pu}(\mathrm{IV})$. Threedifferent types of HOPO-SAMMS were studied in this work, 1,2-HOPOBn-6-carboxylic acid, N-methyl3,2-HOPOBn-4-carboxylic acid, and 2-methyl-3,4-HOPOBn-N-acetic acid. They found that the 1,2HOPO-SAMMS has higher binding affinity to U(VI) than 3,2-HOPO-SAMMS as shown by higher distribution coefficient. However, the 3,2-HOPO-SAMMS has the best performance for removing $\mathrm{Np}(\mathrm{V})$ 
whereas 3,4-HOPO-SAMMS has the lowest performance to sequestrate these three metal ions. Mureseanu [6] modified the surface of mesoporous silica SBA-15 by N-Propylsalicylaldimino and used as adsorbent for heavy metal removal. The sorbent material showed high adsorption capacity and high selectivity for $\mathrm{Cu}(\mathrm{II})$, $\mathrm{Ni}(\mathrm{II}), \mathrm{Zn}(\mathrm{II})$, and $\mathrm{Co}(\mathrm{II})$ and it could be easily regenerated by acid treatment. Aguado [12] studied the performances of amine-functionalized mesoporous silica SBA-15 for heavy metal ions removal from solution. Three different functional groups were investigated in this work, aminopropyl, [2aminoethylamino]-propyl, and [(2-aminoethylamino)-ethylamino]-propyl. It was observed that different functional groups has different selectivity to different metal ions of which aminopropyl selectively bound to $\mathrm{Pb}$ (II) $>>\mathrm{Cd}$ (II) $>>\mathrm{Zn}$ (II) $>\mathrm{Cu}$ (II) $>\mathrm{Ni}$ (II), [2-aminoethylamino]-propyl could adsorb $\mathrm{Pb}$ (II) $>>\mathrm{Cu}$ (II) $>$ $\mathrm{Zn}(\mathrm{II})>\mathrm{Cd}$ (II) $>\mathrm{Ni}$ (II), and [(2-aminoethylamino)-ethylamino]-propyl was able to bind to $\mathrm{Pb}$ (II) $>>$ $\mathrm{Cu}(\mathrm{II})>\mathrm{Cd}(\mathrm{II})>\mathrm{Zn}(\mathrm{II})>\mathrm{Ni}(\mathrm{II})$. It is noted however that all adsorbents show high sorption performances for all metal ions in this study of which fast adsorption rate was observed and the adsorbents could perform very well at even very low metal ion concentration of $5 \mathrm{mg} \mathrm{L}^{-1}$.

Wang [27] investigated the capability of superparamagnetic iron oxide $\left(\mathrm{Fe}_{3} \mathrm{O}_{4}\right)$ nanoparticles modified by dimercaptosuccinic acid (DMSA) to remove toxic soft metals, such as $\mathrm{Hg}, \mathrm{Ag}, \mathrm{Pb}, \mathrm{Cd}$, and $\mathrm{Tl}$, from different sources, including river water, groundwater, seawater, and human blood and plasma. The DMSA$\mathrm{Fe}_{3} \mathrm{O}_{4}$ was proved to be an excellent sorbent for toxic removal with a 30-fold higher capability than GT-73, a commercial resin based sorbent. Moreover, adsorption kinetic of DMSA-Fe $\mathrm{O}_{4}$ is faster than that of GT73 at a similar adsorption concentration. Such observed phenomena are due to the unique properties of DMSA-Fe $\mathrm{O}_{4}$, of which the functional groups have high binding affinity to metal ions while a large surface area of $\mathrm{Fe}_{3} \mathrm{O}_{4}$ nanoparticle facilitate the adsorption kinetic. Ballesteros and colleagues [28] studied adsorption behavior of pirymidine-modified mesoporous silica MCM-41, named LDAPY-MCM-41, in aqueous solution. Selectivity of the adsorbent investigated with three metal ions, $\mathrm{Cu}(\mathrm{II}), \mathrm{Ni}(\mathrm{II})$, and $\mathrm{Co}(\mathrm{II})$, showed that the LDAPY-MCM-41 preferentially bind to $\mathrm{Cu}$ (II) rather than $\mathrm{Ni}(\mathrm{II})$ and $\mathrm{Co}(\mathrm{II})$, respectively. The maximum adsorption of $\mathrm{Cu}$ (II) of $2.976 \mathrm{mM} \mathrm{g}^{-1}$ was found at $\mathrm{pH}$. This might be because $\mathrm{Cu}$ (II) can access to interact with amino groups of LDAPY-MCM-41 easier than the others.

Perez-Quintanilla et al. [24] examined the use of modified-functionalized mesoporous silica to sequestrate $\mathrm{Zn}$ (II) from solution. In this work, 5-mercapto-1-methyltetrazole (MTTZ) was used as functional group to modify surface of HMS and MSU-2 mesoporous silica. High surface coverage and pore size of the hybrid sorbent materials showed high adsorption capacityof $\mathrm{Zn}$ (II) in solution of $0.94 \mathrm{mmol}$ $\mathrm{Zn}$ (II) per gram of MTTZ-MSU-2 and $0.72 \mathrm{mmol} \mathrm{Zn(II)} \mathrm{per} \mathrm{gram} \mathrm{of} \mathrm{MTTZ-HMS} \mathrm{at} \mathrm{pH}$ 8. Higher adsorption observed in case of MTTZ-MSU-2 is due to its high surface area and pore diameter. Selectively adsorption behavior of these materials was also further investigated in this work by studying adsorption capacity of $\mathrm{Zn}$ (II) in solution containing co-existing metal ions including $\mathrm{Pb}(\mathrm{II}), \mathrm{Cd}$ (II), $\mathrm{Cu}$ (II), and $\mathrm{Cr}(\mathrm{III})$. The results revealed that at $\mathrm{pH} 8$ the sorbent material, MTTZ-MSU-2, could adsorb $\mathrm{Zn}(\mathrm{II}) \sim \mathrm{Pb}(\mathrm{II})>>\mathrm{Cd}(\mathrm{II})>\mathrm{Cu}(\mathrm{II})>\mathrm{Cr}(\mathrm{III})$. Liu et al. [29] proposed the effect of molecular length and structure of polyamines-functionalized poly(glycidyl methacrylate) (PGMA) on performances of $\mathrm{Cu}$ (II) removal. Four different types of aliphatic polyamines were investigated in this study: ethylenediamine (EDA), diethylenetriamine (DETA), triethylenetetramine (TETA), and tetraethylenepentamine (TEPA). It was found that an amount of $\mathrm{Cu}$ (II) uptake followed the order of DETA>TETA>EDA>TEPA as revealed by the average coordination number of copper as the lowest coordination for copper ion-adsorbed was observed with the DETA-PGMA. This is because the DETA has lowest nitrogen atoms in the coordination. Wu et al. [30] synthesized thiol-functionalized mesoporous silica for separation of heavy metal ions from water. Analysis of adsorption isotherms showed high performances for removing $\mathrm{Cu}$ (II), $\mathrm{Pb}(\mathrm{II}), \operatorname{Ag}(\mathrm{II})$, and $\mathrm{Cr}(\mathrm{III})$, and removal rate was high and the adsorbent could be regenerated by acid treatment without changing its properties.

Alothman and Apblett [31] studied the capability of mesoporous silica functionalized with di-, tri-, or penta-amine groups for $\mathrm{Cu}(\mathrm{II}), \mathrm{Zn}(\mathrm{II})$, and $\mathrm{Cd}(\mathrm{II})$ ions sequestration from aqueous solutions. Experimental results revealed that all amines exhibited high potential for removal the metal ions in similar tendency of $\mathrm{Cu}(\mathrm{II})>\mathrm{Zn}(\mathrm{II})>\mathrm{Cd}(\mathrm{II})$. Among these functional groups, it was observed that the ethylenediamine functional group has the highest chemisorption capacity for all metal ions at its optimum condition: $\mathrm{Cu}(\mathrm{II})$ at $\mathrm{pH} 5.5$, $\mathrm{Zn}$ (II) at $\mathrm{pH} 6$, and $\mathrm{Cd}$ (II) at $\mathrm{pH}$ 7.0. It is noted from the results of this study that increasing polyamine chain length did not lead to an increase in sorption capacity. Moreover, it is noted that the effect of amine groups observed in this work is different from those observed by Liu et al. [29]. This phenomenon suggests that metal ion adsorption performance also depends upon supported material. It was claimed by Liu et al. [29] that polyamine density was hindered as it might interact with PGMA more than one reaction site. 
Table 1 summarizes examples of functional groups of modified-functionalized nanoporous support adsorbent that have been investigated to sequestrate metal ions from solution.

Table 1. Examples of functional groups used to modify nanoporous material surface to remove metal ions.

\begin{tabular}{|c|c|c|c|c|c|}
\hline \multirow[b]{2}{*}{ Functional groups } & \multirow[b]{2}{*}{$\begin{array}{c}\text { Metal } \\
\text { ions }\end{array}$} & \multirow[b]{2}{*}{$\begin{array}{c}\mathrm{pH} \text { of } \\
\text { solution }\end{array}$} & \multirow{2}{*}{$\begin{array}{c}\text { Initial metal } \\
\text { ion } \\
\text { concentration } \\
\quad\left(\mathrm{mg} \mathrm{L}^{-1}\right)\end{array}$} & \multirow[b]{2}{*}{$\%$ Removal } & \multirow[b]{2}{*}{ References } \\
\hline & & & & & \\
\hline Aminopropyl & $\mathrm{Zn}^{2+}$ & $7-9$ & 65 & $\sim 100 \%$ & [7] \\
\hline Mercaptopropyl & $\mathrm{Zn}^{2+}$ & 8 & 65 & $\sim 100 \%$ & \\
\hline Vinyl & $\mathrm{Zn}^{2+}$ & 10.5 & 65 & $\sim 100 \%$ & \\
\hline Phenyl & $\mathrm{Zn}^{2+}$ & 10.5 & 65 & $\sim 100 \%$ & \\
\hline Cyanopropyl & $\mathrm{Zn}^{2+}$ & 10.5 & 65 & $\sim 100 \%$ & \\
\hline Aminopropyl & $\mathrm{Pb}^{2+}$ & $\mathrm{N} / \mathrm{A}$ & 100 & $\sim 99 \%$ & [12] \\
\hline Ethyldiaminopropyl & $\mathrm{Pb}^{2+}$ & $\mathrm{N} / \mathrm{A}$ & 100 & $\sim 99 \%$ & \\
\hline Dimercaptosuccinic acid & $\mathrm{Pb}^{2+}$ & 7 & 1 & $\sim 99 \%$ & [32] \\
\hline \multirow[t]{3}{*}{ Melamine-based dendrimer amine } & $\mathrm{Pb}^{2+}$ & $3-5$ & 100 & $100 \%$ & [33] \\
\hline & $\mathrm{Cd}^{2+}$ & 4 & 100 & $71 \%$ & \\
\hline & $\mathrm{Cu}^{2+}$ & $4-5$ & 100 & $100 \%$ & \\
\hline
\end{tabular}

\subsection{Proposed Mechanism of Modified-Functionalized Nanoporous Support}

Modification surface of nanoporous adsorbent by organic materials have been developed to increase selectivity to target metals apart from high adsorption capacity of conventional porous materials. The organic materials are chosen in such a way that one side of the molecules should contain charges or polar groups that have ability to preferentially interact with metal ions of interest whereas another side should be atoms or molecules that have ability to connect to nanoporous surface. As such, surfactant is one of good choices to use as functional groups in modified-functionalized nanoporous adsorbent.

In adsorption system, the adsorption of metal ions on modified-functionalized nanoporous support mostly involves a solid phase (adsorbent) and a liquid phase (solution of metal ions). The mechanism relies mainly on attractive electrostatic interaction between metal ions and functional groups that contain different charges depend upon environmental solution [8]. Schematic of adsorption mechanism of modified-functionalized nanoporous support is demonstrated in Fig. 1.

Generally, different systems comprise of different parameters that can affect the system efficiency, as such in order to determine optimum operating condition for the system of interest, it is necessary to consider the effect of such parameters. There are many variable parameters that can influent adsorption performance of this hybrid adsorbent such as $\mathrm{pH}$ of solution, valence or size of functional group, temperature, type of support material, pore size and surface area of support material, initial concentration of metal ions, or contact time, etc.

Selection of appropriate functional groups is one of the important factors that is needed to consider in order to maximize the efficiency of adsorption system. Because the adsorption of metal ions on adsorbent is mostly due to electrostatic attraction between target metals and functional groups, as such compatibility between charges of metal and of functional groups is needed to be considered. The compatibility between target metals and adsorbents has been classified by different concepts such as hard and soft acid-base concept [34] or size and valence matching. It has been proposed that the smaller radius and higher valence, the closer and stronger interactions [35]. 


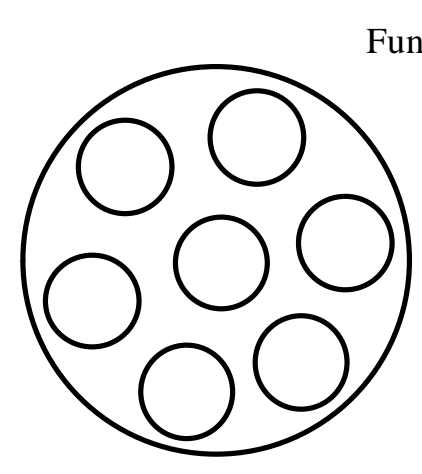

Porous material
Functional groups
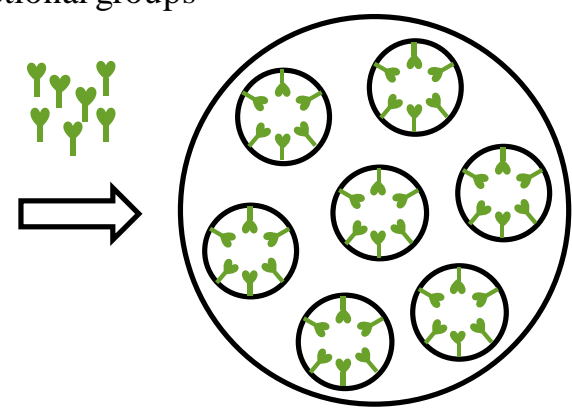

Modified-functionalized nanoporous support
Metal ions

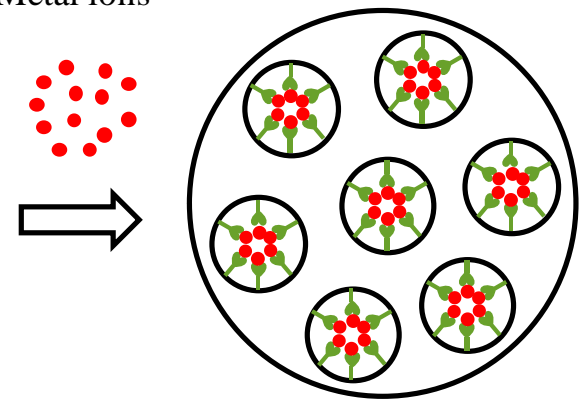

Adsorbent with metal ion adsorption

Fig. 1. Mechanism of adsorption by modified-functionalized nanoporous support adsorbent.

Wastewater treatment process is a process that likely mostly uses the modified-functionalized nanoporous adsorbent. Solution $\mathrm{pH}$ is therefore become one of influence factors on adsorption of metal ions on adsorbents as ionic states of either functional groups or metal ions can alter when $\mathrm{pH}$ of solution is changed, which could affect the formation of metal ion-adsorbent complexes and hence adsorption efficiency. Changing solution $\mathrm{pH}$ leads to the change of $\mathrm{H}^{+}$or $\mathrm{OH}^{-}$, resulting in the change of the degree of ionization, adsorption rate, and adsorption capacity of the system. One concept that can be used to determine proper $\mathrm{pH}$ solution of the system is the consideration of zero point charge of functional groups. The zero point charge is a $\mathrm{pH}$ at which the total charge on the functional groups is zero. When the $\mathrm{pH}$ of solution is less than the zero point charge of the functional groups, the surface charges are positive. On the other hand, if the $\mathrm{pH}$ of solution is higher than zero point charge of the functional groups of the adsorbent, the surface of the adsorbent possesses negative one. It is worth to note that charge state of metal ion is also decided by $\mathrm{pH}$ of solution. Most metal ions precipitate out in basic region as the ions react with $\mathrm{OH}^{-}$ions forming metal hydroxide complex molecules, which does not contribute to adsorption process.

Temperature is another important factor that could alter the adsorption ability. The change of temperature can lead to the change in thermodynamics and kinetic energy. Thermodynamics data such as Gibbs free energy $(\Delta G)$, enthalpy $(\Delta H)$, and entropy $(\Delta S)$, which are known that depend on the temperature of the system, can tell us the feasibility and spontaneity of the process. Negative value of $\Delta G$ indicates that the process can occur spontaneously and vice versa for the positive value. The value of $\Delta H$ reveals the direction of energy in the system, positive values indicate endothermic whereas negative values designate exothermic process. The value of $\Delta S$ demonstrates the order or disorder of the system, which in this case represents by the structure of metal-adsorbent at the interface. Negative values of $\Delta S$ show a decrease of disorder structure at the ion-adsorbent interface and vice versa for positive values of $\Delta S$. Hence, examining thermodynamics data could notify if the adsorption process of interest can be used for metal treatment at different temperatures. Apart from thermodynamics point of view, the change of temperature also affects kinetic energy of the system as it can enhance or retard the diffusion rate of the ions. In general, increasing temperature can increase the movement of metal ions resulting in fast adsorption rate [8].

Other parameters that can affect the efficiency of adsorption are, for example, initial concentration of metal ion as it is observed that removal capability increases with increasing initial ion concentration as this can enhance ion gradient to the vacant active site of the adsorbent [33]. Adsorption ability also depends upon the arrangement of functional groups on porous support as strong and stability adsorption can be obtained if multiple coordination sites are associated [36].

Combination of the unique characteristic of surfactant and nanoporous material in modifiedfunctionalized nanoporous adsorbent makes this material become a potential adsorbent for metal sequestration purpose. The strengths of this hybrid adsorbent over conventional adsorbent are high selectivity, high adsorption capacity at even very low metal ion concentration, high stability, and fast sorption kinetics, where equilibrium can be reached quickly. In addition, another spotlighted-feature of modified-functionalized nanoporous support is that the solid phase of the adsorbent could be further developed and designed as a packed bed adsorbent, which is beneficial for continuous metal sequestration 
process in industrial scale. However, at the present, the inherent difficulty in applying the modifiedfunctionalized nanoporous adsorbent for large scale applications are still encounter due to their complicated synthesis.

\section{Conclusion}

Surfactants are proven to be versatile materials as they can serve high potential efficiency in many areas such as manufacturing of chemical, food, cosmetic, petroleum, etc. In the past decades, surfactants have been extended the use to environmental application of the removal of metal ions from different matrices such as wastewater, drinking water, ground water, or soil. The use of surfactants can enhance removal efficiency of membrane as the formation of micelle can capture metal ions and form molecule complexes, resulting in a reduction of high pressure needed for membrane process. This process is called micellarenhanced ultrafiltration (MEUF). However, the drawback of this technique is that it is difficult to apply for continuous operating due to membrane blockage. Another technique that is developed to enhance the ability of heavy metal removal processes with the application of surfactants is the use of surfactants connected to nanoporous material, known as modified-functionalized nanoporous support. The distinction of this adsorbent relies on the fact that the functional groups (organic materials or surfactants) can interact selectively with target metal ions while the nanoporous support provides high surface area, leading to high binding capacity. However, the drawback of this technique is the difficulty in synthesising the adsorbent.

\section{Acknowledgements}

The authors would like to acknowledge National Research Universities, the Office of the Higher Education Commission, Silpakorn University Research and Development Institute, and Thai Government Science and Technology Scholarship Students (CSTS), National Science and Technology Development Agency (NSTDA) for financial support.

\section{References}

[1] D. F. Evans and W. Hakan, "Solutes and solvents, self-assembly of amphiphiles," in The Colloidal Domain: Where Physics, Chemistry, Biology, and Technology Meet, 2nd ed. Canada: Wiley-VCH, 1999, ch. 1, sec. 1, pp. 5-9.

[2] M. J. Rosen, "Characteristic features of surfactants," in Surfactants and interfacial phenomena, 3rd Ed. John Wiley \& Sons, Inc., 2004, ch. 1, pp. 1-32.

[3] K. K. Singh, A. K.Singh, and S. H. Hasan, "Low cost bio-surfactant 'wheat bran' for the removal of cadmium from wastewater: Kinetic and equilibium studies," Bioresource Technol, vol. 97, no. 8, pp. 9941001, May 2006.

[4] G. E. Fryxell, H. Wu, Y. Lin, J. W. Shaw, C. J. Birnbaum, C. J. Linehan, Z. Nie, K. Kemner, and S. Kelly "Lanthanide selective sorbents: self-assembled monolayers on mesoporous supports (SAMMS)," J. Mater. Chem., vol. 14, no. 22, pp. 3356-3363, September 2004.

[5] W. Yantasee, "Simultaneous detection of cadmium, copper, and lead using a carbon paste electrode modified with carbamoylphosphonic acid self-assembled monolayer on mesoporous silica (SAMMS)," Anal Chim Acta., vol. 502, no. 2, pp. 207-212, January 2004.

[6] M. Mureseanu, "Modified SBA-15 mesoporous silica for heavy metal ions remediation," Chemosphere, vol. 73, no. 9, pp. 1499-1504, August 2008.

[7] M. Barczak, E. Skwarek, W. Janusz, A. Dabrowski, and S. Pikus, "Functionalized SBA-15 organosilicas as sorbents of zinc (II) ions," Appl Surf Sci, vol. 256, no. 17, pp. 5370-5375, June 2010.

[8] U. Farooq, J. A. Kozinski, M. A. Khan, and M. Athar, "Biosorption of heavy metal ions using wheat based biosorbents-A revies of the recent literature," Bioresource Technol, vol. 101, no. 14, pp. 5043-5053, March 2010.

[9] F. Fu and Q. Wang, "Removal of heavy metal ions from wastewaters: A review," J. Environ Manage, vol. 92, no. 3, pp. 407-418, March 2011.

[10] C. N. Mulligan, "Environmental applications for biosurfactants," Environ Pollut, vol. 133, no. 2, pp. 183-198, Jan 2005. 
[11] J. F. Scamehorn, S. D. Christian, D. A. El-Sayed, H. Uchiyama, and S. S. Younis, "Removal of divalent metal cation and their mixtures from aqueous stream using micellar enhanced ultrafiltration." Sep Sci Technol, vol. 29, pp. 809-830, 1994.

[12] J. Aguado, M. J. Arsuaga, A. Arencibia, M. Lindo, and V. Gascon, "Aqueous heavy metals removal by adsorption on amine-functionalized mesoporous silica," J Hazard Mater., vol. 163, no. 1, pp. 213-221, April 2009.

[13] X. Li, G. M. Zeng, J. H. Huang, C. Zhang, Y. Y. Fang, Y. H. Qu, F. Luo, D. Lin, and H. L. Liu, "Recovery and reuse of surfactant SDS from a MEUF retentate containing $\mathrm{Cd}^{2+}$ or $\mathrm{Zn}^{2+}$ by ultrafiltration," J. Membrane Sci, vol. 337, no. 1-2, pp. 92-97, July 2009.

[14] C. N. Mulligan, R. N. Young, and B. F. Gibbs, "Heavy metal removal from sediments by biosurfactants," J. Hazard Mater, vol. 85, no. 1-2, pp. 111-125, July 2001.

[15] C. W. Candida and J. H. Harwell., "Surfactants and subsurfactant remediation," Environ. Sci: Technol, vol. 26, no. 12, pp. 2324-2339, December 1992.

[16] S. Akita, L. Yang, and H. Takeuchi, "Micellar-enhanced ultrafiltration of gold(III) with nonionic surfactant," J. Membrane Sci, vol.133, no. 2, pp.189-194, October 1997.

[17] Y. H. Li, "Adsorption of cadmium (II) from aqueous solution by surface oxidized carbon nanotubes," Carbon, vol. 41, no. 5, pp. 1057-1062, April 2003.

[18] T. Gebremedhin-Haile, M. T. Olguin, and M. Solache-Rios, "Removal of mercury ions from mixed aqueous metal solution by natural and modified zeolitic minerals," Water Air Soil Poll, vol. 148, no. 1-4, pp. 179-200, April 2003.

[19] Y. G. Ko and U. S. Choi, "Observation of metal ions adsorption on novel polymeric chelating fiber and activated carbon fiber," Sep Purif Technol, vol. 57, no. 2, pp. 338-347, October 2007.

[20] B. Lebeau, F. Gaslain, C. F. Martin, and F. Babonneau, "Organically modified ordered mesoporous siliceous solids," in Ordered Porous Solids, 2009, ch. 11, pp. 283-308.

[21] P. J. Majewski, "Removal of organic matter in water by functionalized self-assembled monolayer on silica," Sep Purif Technol, vol. 57, no. 2, pp. 283-288, October 2007.

[22] W. Yantasee, Y. Lin, G. E. Fryxell, J. B. Busche, and C. J. Birnbaum, "Removal of heavy metals from aqueous solution using novel nanoengineered sorbent: Self-assembled carbamoylphosphonic acids on mesoporous silica," Sep Sci Tecbnol, vol. 38, no. 15, pp. 3809-3825, August 2003.

[23] G. E. Fryxell, Y. Lin, H. Wu, and K. M. Kemer, "Environmetal applications of self-assembled monolayers on mesoporous supports (SAMMS)," Nanoporous Materials III, Proceedings of the 3rd International Symposium on Nanoporous Materials, vol. 141, pp. 583-590, June 2002.

[24] D. Perez-Quintanilla, A. Sanchez, I. D. Hierro, M. Fajardo, and I. Sierra, "New hybrid materials as Zn(II) sorbents in water samples," Mater Res Bull, vol. 45, no. 9, pp. 1177-1181, September 2010.

[25] G. E. Fryxell, Y. Sandyfiskum, C. J. Birnbaum, and H. Wu, "Actinide sequestration using selfassembled monolayers on mesoporous supports," Environ Sci Technol, vol. 39, no. 5, pp. 1324-1331, January 2005.

[26] Y. Lin, S. K. Fiskum, W. Yantasee, H. Wu, S. Mattigod, E. Vorpagel, and G. E. Fryxell, "Incorporation of hydroxypyridinone ligands into self-assembled monolayers on mesoporous supports for selective actinide sequestration," Environ Sci Technol, vol. 39, no. 5, pp. 1332-1337, March 2005.

[27] P. Wang, "Preparation of magnetic iron/mesoporous silica composite spheres and their use in protein immobilization," Transactions of Nonferrous Metals Society of China, vol. 19, no. 3, pp. 605-610, December 2009.

[28] R. Ballesteros, D. Perez-Quintanilla, M. Fajardo, I. D. Hierro, and I. Sierra, "Adsorption of heavy metals by pirymidine-derivated mesoporous hybrid material," J. Porous Mat, vol. 17, no. 4, pp. 417-424, 2009.

[29] C. Liu, R. Bai, L. Hong, and T. Liu, "Functionalization of adsorbent with different aliphatic polyamines for heavy metal ion removal: Characteristics and performance," J. Colloid and Interf Sci, vol. 345, no. 2, pp. 454-460, January 2010.

[30] S. Wu, F. Li, R. Xu, S. Wei, and G. Li, "Synthesis of thiol-functionalized MCM-41 mesoporous silicas and its application in $\mathrm{Cu}(\mathrm{II}), \mathrm{Pb}(\mathrm{II}), \mathrm{Ag}(\mathrm{I})$, and $\mathrm{Cr}(\mathrm{III})$ removal," J. Nanopart Res, vol. 12, no. 6, pp. 2111-2124, August 2010.

[31] A. Z. Alothman and W. A. Apblett, "Metal ion adsorption using polyamine-functionalized mesoporous materials prepared from bromopropyl-functionalized mesoporous silica," J. Hazard Mater, vol. 182, no. 1-3, pp. 581-590, June 2010. 
[32] W. Yantasee, C. L. Warner, T. Sangvanich, R. S.Addleman, T. G. Carter, R. J. Wiacek, G. E. Fryxell, C. Timchalk, and M. G. Warner, "Removal of heavy metals from aqueous systems with thiol functionalized superparamagnetic nanoparticles," Environ. Sci. Technol., vol. 41, no. 14, pp. 5114-5119, June 2007.

[33] A. Shahbazi, H. Younesi, and A. Badiei, "Functionalized SBA-15 mesoporous silica by melaminebased dendrimer amines for adsorptive characteristics of $\mathrm{Pb}$ (II), $\mathrm{CU}$ (II) and $\mathrm{Cd}$ (II) heavy metal ions in batch and fixed bed column," Chem Eng J., vol. 168, no. 2, pp. 505-518, April 2011.

[34] B. Volesky, "Biosorption process simulation tools," Hydrometallurgy, vol. 71, no. 1-2, pp. 179-190, October 2003.

[35] P. Wu and Y. S. Zhou, "Simultaneous removal of coexistent heavy metals from simulated urban stormwater using four sorbents: A porous iron sorbent and its mixtures with zeolite and crystal gravel," J. Hazard Mater, vol. 168, no. 2-3, pp. 674-680, February 2009.

[36] H. Youshitake, "Design of functionalization and structural analysis of organically-modified siliceous oxides with periodic structures for the development of sorbents for hazardous substances," J. Mater Chem, vol. 20, no. 22, pp. 4537-4550, March 2010. 
